cual termina restándole valor, e impidiendo que puedan tener la solvencia de las de los grandes especialistas: Albrigth, Gardiner, Rainey, Sass, Goldwasser, Wilson-Wright, etc.

Pablo Díez Herrera

Facultad de Teología San Isidoro de Sevilla pablodiezherrera@gmail.com

\title{
Gianfranco Ravasi, Adán ¿dónde estás? Preguntas antropológicas contemporáneas (BAC Popular 244), Madrid, Biblioteca de Autores Cristianos, 2020, 69 pp., $9 €$.
}

https://doi.org/10.46543/ISID.2029.1010

El autor de este libro es Cardenal Presidente del Pontificio Consejo de la Cultura. Estudioso de la Sagrada Escritura, infatigable y ávido lector, con prodigiosa memoria, Gianfranco Ravasi es uno de los biblistas más conocidos y consultados actualmente en Italia. Tiene en su haber gran cantidad de ensayos, obras de divulgación y comentarios exegéticos de amplio calado. Se prodiga como conferenciante, colaborando también asiduamente en revistas, como Vida Nueva, y en periódicos como el diario Avvenire, L'Osservatore Romano o Il Sole 24 Ore. Son muy apreciadas sus frecuentes intervenciones en televisión, donde participa en diversos programas culturales. Su presencia en las redes sociales es igualmente sobresaliente, con numerosos seguidores. Todo esto le viene por su brillante dominio de la palabra escrita, siendo asimismo un placer escucharlo por su claridad expositiva, la riqueza y variedad de los autores que cita y sus grandes dotes de orador.

La obra que presentamos es breve en extensión y honda en su contenido. Digno de mención es el prólogo del volumen, redactado por el Subsecretario del Pontificio Consejo de la Cultura, Mons. Melchor Sánchez de Toca. Subrayo asimismo la belleza de la traducción del texto italiano al español, llevada a cabo con esmero por Pedro Ignacio Fraile Yécora, competente biblista. Ha sido igualmente un acierto que la presente edición contenga notas a pie de página, unas de carácter explicativo, para glosar cierta terminología usada por el autor, y otras indicadoras de la versión castellana de determinados libros citados por Ravasi en el cuerpo del texto.

En siete enjundiosos capítulos, el Purpurado, partiendo de la pregunta de Dios a Adán en el paraíso: “¿Dónde estás?" (Gén 3,9), formula sabias interpelaciones para esclarecer la hodierna situación existencial del ser humano. Leyendo estas páginas, percibimos que esa primordial interpelación divina no es una pregunta que pueda simplemente quedar atenazada en 
el pasado. Antes bien, en cierta manera, es una cuestión eterna, que sigue resonando con pujanza en la hora presente.

Con sus reflexiones, el Cardenal invita al lector a dejar a un lado la superficialidad para iniciar un camino de búsqueda y hondura en un tiempo en el que, tal vez, las conquistas técnicas y científicas nos hayan deslumbrado, fascinado incluso, convenciéndonos de capacidades que no tenemos, sumergiéndonos en sueños que acabaron siendo solo embaucadores. Acostumbrados a vivir corriendo, a toda velocidad, sumidos en una vorágine de prisas, hemos perdido el valor del fin. Atiborrados de medios, no miramos la meta hacia la que nos encaminamos, ni nos preguntamos cuál es el sentido de nuestro destino. Hemos de detenernos y pensar. Entonces nos daremos cuenta de que el "¿dónde estás?", dirigido al primer hombre en la Biblia, en realidad, no es algo meramente geográfico. Se convierte en una pregunta que afecta a todo hombre y que le plantea el objeto de su existencia, el propósito de sus esfuerzos. Se trata de percibir sin engaño el para qué de nuestra vida y obra: "Hombre, ¿adónde vas?".

Descubierta esta clave, el libro arranca con un planteamiento: lo importante para madurar y superarnos son las interpelaciones. Preguntar con tino es más un arte de maestros que de discípulos. Hay que haber estudiado mucho para saber lo que se ignora e individuar lo que merece la pena ser comprendido. En un mundo que acumula datos y devora informaciones, Ravasi pone de relieve que es mejor tener una cabeza ordenada que simplemente llena. Pensamos que hay que tener respuestas para todo, cuando en verdad lo que cuenta es tener una pregunta acertada para cada cosa. Si nos detenemos, observamos que una respuesta está al alcance de cualquiera. Hay cantidad ingente de respuestas, muchas de ellas falsas, banales e inconsistentes. Son, por el contrario, las preguntas, la genialidad para interrogarse, lo que manifiesta la inteligencia de la persona. Partiendo de ese fundamento, el autor de esta sucinta monografía recopila algunos de los interrogantes sustanciales que tenemos planteados en nuestros días. Muchos de ellos han sido puestos por la tecnología, la informática y las ciencias.

Al hilo de las cuestiones, Ravasi, más que recoger respuestas nutridas, apunta pistas de orientación, señala claves de comprensión, muchas de ellas resultado de un granado humanismo. El autor ofrece, de este modo, concisas respuestas trayendo a colación un surtido abanico de textos antiguos y nuevos, fruto de la pluma de variopintos escritores, filósofos, historiadores, literatos del ayer y del hoy, etc. Naturalmente, en sus consideraciones, abunda la divina Palabra, pues su luz es inmarcesible y traspasa los siglos, brindando un anclaje seguro en tiempos de intemperie. Ravasi muestra de esta forma que la conjunción de pasado y presente es siempre fecunda. Es de necios despreciar o rechazar a quienes nos precedieron en un alarde de ser modernos a toda costa. Más aún, haber destruido pilares sobre los que 
se asentaron pueblos, y que revelaron su validez durante centurias, ha sido una de las decisiones más nefastas que el hombre de hoy ha tomado y cuyas consecuencias todavía son difíciles de vislumbrar en toda su magnitud. Se requiere un discernimiento, pues no se trata de conservar en bloque, pero tampoco de satanizar lo nuevo. Es cuestión más bien de descubrir qué retos actuales ofrecen posibilidades viables, positivas y feraces, dignas de ser cultivadas y desplegadas por alguien con sed de sentido y plenitud.

Estas páginas testimonian que G. Ravasi, en lugar de escoger la senda de la crítica estéril o la constante queja por el declinar de un mundo que se abisma en no pocas ocasiones y temáticas en negras oscuridades, ha optado por la pregunta como instrumento hermenéutico para divisar horizontes despejados. A este respecto, el Cardenal hace suyo el programa que ya había esbozado Spinoza en su Tractatus politicus (I,4): "He procurado con empeño no reírme de las acciones humanas, no deplorarlas ni condenarlas, sino entenderlas". Ahora bien, en el ejercicio de comprender la realidad va incluido el de escrutar, como enseña san Pablo en su primera carta a los Tesalonicenses: "Examinadlo todo, quedaos con lo que es bello y bueno" $(5,21)$ (pág. 13). Desde esta atalaya y con esta perspectiva, el Purpurado impulsa al lector a polarizar su atención sobre algunas facetas fundamentales de nuestra existencia: el concepto de naturaleza humana; el binomio hombre-mujer; los avances científicos en los ámbitos de la genética, la neurociencia y la inteligencia artificial; el trans-/poshumanismo y la infosfera. Para finalizar, Ravasi ahonda los lazos que vinculan la sensibilidad moderna y la Encarnación.

Concluyendo, esta obra es un brioso acicate, pues sirve para despertarnos de cierta modorra en la que no pocas veces sucumbe nuestro pensamiento. Con sus interpelaciones, el autor clava un aguijón en nuestra carne para alejarnos de tendencias que suelen amoldarnos a tópicos usuales, intencionados y, a menudo, monopolizadores. Con Ravasi se nada contra corriente, para llegar a mares abiertos, con la voluntad de explorar territorios ignotos y anhelantes de vida genuina. A esto mismo nos alienta el Santo Padre cuando afirma, en su encíclica Laudato sì: "Está pendiente el desarrollo de una nueva síntesis que supere falsas dialécticas de los últimos siglos. El mismo cristianismo, manteniéndose fiel a su identidad y al tesoro de verdad que recibió de Jesucristo, siempre se repiensa y se reexpresa en el diálogo con las nuevas situaciones históricas, dejando brotar así su eterna novedad" (n. 121).

Fernando Chica Arellano

Observador Permanente de la Santa Sede ante la FAO, el FIDA, y el PMA arellano@libero.it 